\title{
Contribution of Polysynaptic Pathways in the Mediation and Plasticity of Aplysia Gill and Siphon Withdrawal Reflex: Evidence for Differential Modulation
}

\author{
Louis-Eric Trudeau and Vincent F. Castellucci \\ Laboratoire de Neurobiologie et Comportement, Institut de Recherches Cliniques de Montréal, Montréal, \\ Québec H2W 1R7, Canada and Centre de Recherches en Sciences Neurologiques, Université de Montréal, \\ Montréal, Québec H3C 3J7, Canada
}

The gill and siphon withdrawal (GSW) reflex of Aplysia is centrally mediated by a monosynaptic and a polysynaptic pathway between sensory and motor neurons. The first objective of this article was to evaluate quantitatively the relative importance of these two components in the mediation of the GSW reflex. We have used an artificial sea water (ASW) solution containing a high concentration of divalent cations to raise the action potential threshold of the interneurons without affecting the monosynaptic component of the reflex (2:1 ASW). Compound EPSPs induced in gill or siphon motor neurons by direct stimulation of the siphon nerve or by tactile stimulation of the siphon skin were reduced by more than $75 \%$ in $2: 1$ ASW. These results indicate that interneurons intercalated between sensory and motor neurons are responsible for a considerable proportion of the afferent input to the motor neurons of the reflex. The second objective of this article was to compare the modulation of the monosynaptic and polysynaptic pathways. We have evaluated their respective contribution in sensitization of the GSW reflex by testing the effects of two neuromodulators of the reflex, 5-HT and small cardioactive peptide $\mathbf{B}\left(\mathrm{SCP}_{\mathrm{B}}\right)$. We found that these two neuromodulators have a differential action on the two components of the GSW neuronal network. The polysynaptic pathway was more facilitated than the monosynaptic pathway by the neuropeptide SCP. By contrast, 5-HT displayed an opposite selectivity. These results suggest that the polysynaptic component of the neuronal network underlying the GSW reflex is very important for its mediation. The data also indicate that the monosynaptic and polysynaptic components of the reflex can be differentially modulated. The diversity of modulatory actions at various sites of the GSW network should be relevant for learningassociated modifications in the intact animal.

Received Jan. 29, 1992; revised Mar. 23, 1992; accepted Apr. 28, 1992.

We thank M. Klein and T. Ouimet for a critical reading of the manuscript, $\mathbf{I}$. Morin for preparing the illustrations, and N. Guay for typing the manuscript. This work was funded by Grant MA-10047 from the Medical Research Council of Canada, and by the Richard and Edith Strauss Canada Foundation. L.-E.T. is the recipicnt of a 1967 scholarship from the Conseil de Recherches en Sciences $\mathrm{Na}$ turelles et Génie du Canada.

Correspondence should be addressed to Vincent $F$. Castellucci, Laboratoire de Neurobiologie et Comportement, Institut de Recherches Cliniques de Montréal, 110 Ouest, Avenue des Pins, Montréal, Québec H2W 1R7, Canada.

Copyright (C) 1992 Society for Neuroscience 0270-6474/92/123838-1 $\$ 05.00 / 0$
Although the gill and siphon withdrawal (GSW) reflex of Aplysia californica is mediated by a monosynaptic and a polysynaptic pathway between sensory and motor neurons, most of the efforts aimed at identifying the mechanisms of learning-associated modifications in this neuronal network have focused on the monosynaptic connections between mantle organ sensory neurons and siphon and gill motoneurons (Castellucci et al., 1970, 1980, 1982; Byrne et al., 1974; Castellucci and Kandel, 1976; Dubuc and Castellucci, 1991). These synaptic junctions can be modified for time periods ranging from a few minutes to several days (Frost et al., 1985; Montarolo et al., 1986).

There are, in addition, other sites of synaptic plasticity that have been recognized or suggested in the GSW reflex neuronal network (Jacklet and Rine, 1977; Colebrook and Lukowiak, 1988). In the abdominal ganglion itself, various excitatory and inhibitory interneurons have been identified (Hawkins et al., 1981a; Frost et al., 1988). Several of these interneurons undergo synaptic changes during depression and enhancement of the reflex. The significance of such interneuronal transmission in the mediation of the GSW reflex has, however, not received much attention, and a quantitative evaluation of its importance in the mediation of the total reflex is not available. One report has estimated that approximately $40 \%$ of the evoked input to motoneuron $\mathrm{L} 7$ produced by a brief tactile stimulation to the siphon may be of polysynaptic origin (Byrne et al., 1978). In that study, interneuronal firing was reduced using an extracellular medium containing high concentrations of divalent cations to increase action potential threshold. Because the effect of that medium on monosynaptic transmission was not directly assessed, the contribution of polysynaptic transmission remains unclear. A more quantitative investigation of this component of the centrally mediated part of the reflex was thus warranted. Since the sensory neurons are known to fire only briefly upon siphon stimulation, it is also difficult to explain how the summation of monosynaptic EPSPs could account for the total duration of the reflex contraction. Modeling studies based on physiological data have recently made this point (Frost et al., 1991; White et al., 1991). The observation that facilitation of the GSW reflex is usually associated with both an increased amplitude and duration of the gill contraction (Pinsker et al., 1970) further suggests that the polysynaptic component of the neuronal network may play a crucial role in the mediation and plasticity of the reflex: a potentiation of monosynaptic EPSP amplitudes alone could not account for both the potentiation of reflex amplitude and duration. Enhanced excitatory interneuronal firing, 
subsequent to primary sensory input, could more easily explain the increase in reflex duration during sensitization. These interneurons, together with inhibitory interneurons, could be an important site of plasticity during learning-associated modifications of the reflex.

In this study, we have attempted to evaluate the interneuronal contribution to the mediation and plasticity of the GSW reflex by reversibly reducing the activity of the interneurons in the neuronal network. We have done this by bathing the CNS in a solution with an elevated content of divalent cations to raise the action potential threshold of neurons. We have chosen a medium that did not affect transmitter release at the monosynaptic junctions of the circuit to permit a better estimate of the relative weight of the two components. The modified artificial seawater (ASW) also allowed us to test to what degree the polysynaptic component was affected by two modulators of the withdrawal reflex, 5-HT and small cardioactive peptide $\mathrm{B}\left(\mathrm{SCP}_{\mathrm{B}}\right.$; Brunelli et al., 1976; Abrams et al., 1984). The strategy was to compare the effect of theses substances on evoked compound postsynaptic potentials in motoneurons of the reflex recorded either in the normal or in the modified extracellular medium. We found differential effects of the neuromodulatory agents on the monosynaptic and polysynaptic components of the reflex. The effect of activating endogenous facilitator neurons was also evaluated on the compound postsynaptic potentials. These results should be important for a better understanding of the physiological changes associated with various types of learning in Aplysia; they suggest the possibility that the mechanisms of plasticity within the polysynaptic network may be different from those already identified at the monosynaptic junctions of the neuronal network.

\section{Materials and Methods}

Preparation. Experiments were performed on Aplysia californica (Marinus Inc., Venice, CA) weighing between 100 and $300 \mathrm{gm}$. They were generally housed individually in compartments within a 900 liter artificial seawater tank, and fed dried seaweed (Dulse) triweekly. Animals were anesthetized with an injection of isotonic $\mathrm{MgCl}_{2}$ corresponding to about a third of their volume. Further dissections were then performed with the animal's internal organs and nervous system bathed in a solution made with equal parts of isotonic $\mathrm{MgCl}_{2}$ and artificial seawater (ASW).

For experiments performed on isolated ganglia, the abdominal ganglion was dissected out along with the branchial, genital, and siphon nerves and both pleuroabdominal connectives. The ganglion was then bathed in $0.5 \%$ glutaraldehyde for $15 \mathrm{sec}$ to kill muscle cells; the connective tissue sheath covering the ganglion was removed with fine forceps to expose the neuronal cell bodies. All cut nerves were aspirated into suction electrodes, and the preparation was then allowed to rest for $1 \mathrm{hr}$ with normal ASW being continuously perfused. Some experiments were performed on isolated buccal ganglia that were prepared in the same way as the isolated abdominal ganglia.

In the isolated siphon preparations, the siphon was pinned to the bottom of a large Sylgard-coated chamber $(200 \mathrm{ml})$ and the abdominal ganglion desheathed and pinned in a separate smaller perfusion chamber $(2 \mathrm{ml})$ placed within the larger one. The siphon nerve was allowed to exit the small chamber through a Vaseline-sealed slot. Experimental solutions could thus be manipulated independently in the two compartments. Tactile stimulation of the siphon skin was delivered with an electromechanical stimulator. All nerves, except the siphon nerve, were cut.

Electrophysiology. Neuronal cell bodies were penetrated with either one or two $3 \mathrm{M} \mathrm{KCl}$-filled microelectrodes with resistances between 1 and $15 \mathrm{M} \Omega$. Recordings were made through conventional amplifiers equipped with bridge circuits (Axoclamp 2A, Axon Instruments). Data were stored in parallel on a modificd VHS rccorder (VETTER, model $420 \mathrm{E}$ ) and on a microcomputer; they were then analyzed with the SPIKE data analysis software (Hilal Associates).
In the abdominal ganglion, recordings were made from the LE cluster sensory neurons, L34 excitatory interneurons, and motor neurons L7, LFS, or less frequently, LBS (Kupfermann et al., 1974; Byrne et al., 1978; Frost et al., 1988). The results obtained with the three types of motoneurons were pooled because no differential effects were observed. Experiments were also performed on the right connective monosynaptic EPSP recorded in neuron R15 (Frazier et al., 1967). In the buccal ganglion, neurons B4 or B5 and their follower cells B3 or B6 were used (Tauc and Gerschenfeld, 1962; Gardner, 1971; Baux et al., 1990). The presynaptic neuron was current clamped at $-50 \mathrm{mV}$, and action potentials were elicited by short depolarizing steps. An inhibitory postsynaptic current was thus generated in the voltage-clamped $(-80 \mathrm{mV})$ postsynaptic B3/B6 neuron by the opening of acetylcholine-gated $\mathrm{Cl}^{-}$ channels. As $\mathrm{Cl}^{-}$leaked into the postsynaptic neuron through the electrodes, the equilibrium potential for $\mathrm{Cl}$ ions was gradually altered. This was taken into account by continuously monitoring the equilibrium potential and adjusting the holding potential so as to maintain a constant electrochemical driving force.

Drugs and solutions. Serotonin creatinine sulfate (Sigma) and $\mathrm{SCP}_{\mathrm{B}}$ (small cardioactive peptide B; Richelieu Biotechnologie, Québec) were prepared in ASW and aliquots maintained at $-20^{\circ} \mathrm{C}$ until needed. Modified ASW solutions were used where indicated. The normal ASW contained $\mathrm{NaCl}, 460 \mathrm{~mm} ; \mathrm{CaCl}_{2}, 11 \mathrm{~mm} ; \mathrm{KCl}, 10 \mathrm{~mm} ; \mathrm{MgCl}_{2}, 30 \mathrm{~mm}$; $\mathrm{MgSO}_{4}, 25 \mathrm{~mm}$; and HEPES buffer, $10 \mathrm{~mm}(\mathrm{pH} \mathrm{7.8)}$. The 3:3 ASW solution (which contained three times the normal concentrations of $\mathrm{Mg}^{2+}$ and $\mathrm{Ca}^{3+}$ consistcd of $\mathrm{NaCl}, 328 \mathrm{~mm} ; \mathrm{CaCl}_{2}, 33 \mathrm{~mm} ; \mathrm{KCl}, 10 \mathrm{~mm}$; $\mathrm{MgCl}_{2}, 165 \mathrm{~mm}$; and HEPES buffer, $10 \mathrm{~mm}$ (pH 7.8). The 2:1 ASW solution (which contained 2.2 times the normal concentration of $\mathrm{Mg}^{2+}$ and 1.25 times the normal concentration of $\mathrm{Ca}^{2+}$ ) consisted of $\mathrm{NaCl}$, $368 \mathrm{~mm} ; \mathrm{CaCl}_{2}, 13.8 \mathrm{~mm} ; \mathrm{KCl}, 8 \mathrm{~mm} ; \mathrm{MgCl}_{2}, 101 \mathrm{~mm} ; \mathrm{MgSO}_{4}, 20 \mathrm{~mm}$; and HEPES buffer, $10 \mathrm{mM}$ (pH 7.8). All data presented in the text and figures are expressed as mean \pm standard error of the mean (SEM). Statistical comparisons were made with Student's $t$ test; paired or independent $t$ tests were used where appropriate.

\section{Results}

To investigate the importance of the polysynaptic pathway in the mediation of the GSW reflex, the sensory input from the siphon skin was simulated by applying a short-duration electrical shock directly to the siphon nerve through a suction electrode. Evoked compound EPSPs were recorded in identified motor neurons innervating the gill (L7) or siphon (LFS or LBS). The contribution of interneurons to the compound potentials was evaluated by replacing the normal perfusion solution (ASW) with another containing higher concentrations of divalent cations $\left(\mathrm{Ca}^{2+}\right.$ and $\left.\mathrm{Mg}^{2+}\right)$ to increase the action potential threshold of the interneurons. This procedure permits a reversible reduction or complete removal of the contribution of the polysynaptic pathway to the neuronal circuit. This method will provide a good estimate of the interneuronal contribution only if the modified ASW is shown to have no effect on monosynaptic transmission. The effects of two different solutions (3:3 ASW and 2:1 ASW; see Materials and Methods) were thus tested on monosynaptic transmission at three different types of synapses. The 3:3 medium has been previously used to reduce interneuronal activity (Byrne et al., 1978).

\section{Effects of solutions containing high concentrations of divalent cations on monosynaptic transmission}

A monosynaptic EPSP can be evoked in neuron R15 upon stimulation of the right pleuroabdominal connective (Frazier et al., 1967). The ganglion was perfused first with normal ASW and then successively with the two modified solutions. Figure $1 A$ shows that replacing normal ASW by 3:3 ASW induced a considerable increase in EPSP amplitude. We observed a significant mean increase of $163.5 \pm 29.0 \%$ above control in five preparations $(t=-3.08 ; p<0.05)$. Perfusion with the $2: 1 \mathrm{ASW}$, on the other hand, did not cause any significant change (decrease 

R15 SYNAPSE :

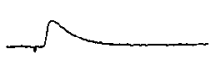

NORMAL ASW

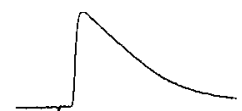

$3: 3$ ASW

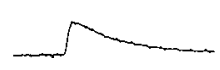

2:1 ASW
B

BUCCAL SYNAPSE :

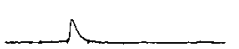

NORMAL ASW
C

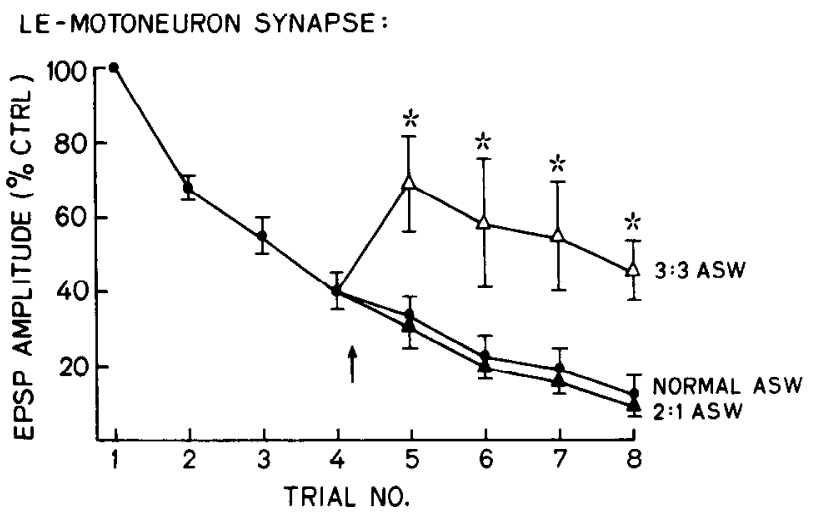

Figure 1. Effect of modified ASWs on monosynaptic transmission. $A$, Monosynaptic EPSPs were recorded in neuron R15 upon brief stimulation of the left pleuroabdominal connective. Replacing the normal ASW by the 3:3 ASW containing three times the normal concentration of $\mathrm{Mg}^{2+}$ and $\mathrm{Ca}^{2+}$ induced an important increase in EPSP amplitude. The 2:1 ASW, containing, respectively, 2.2 times and 1.25 times the normal concentration of $\mathrm{Mg}^{2+}$ and $\mathrm{Ca}^{2+}$, had no significant effect. Calibration: $3 \mathrm{mV}, 50 \mathrm{msec}$. $B$, The same effect was observed at the monosynaptic IPSC recorded between neurons $B 4 / 5$ and $B 3 / 6$ of the buccal ganglion upon threshold stimulation of the presynaptic neuron. Calibration: $350 \mathrm{nS}, 30 \mathrm{msec}$. $C$, EPSPs were recorded in motoneurons upon threshold stimulation of LE sensory neurons of the abdominal ganglion $(n=23)$. Interstimuli interval was 5 min. After the fourth EPSP (arrow), the normal ASW either was replaced with $3: 3 \mathrm{ASW}(n=7)$ or $2: 1 \mathrm{ASW}$ $(n=4)$ or was unchanged $(n=12)$. The $3: 3$ ASW induced an incrcasc in EPSP amplitude. The 2:1 ASW did not interfere with the normal depression of the EPSP. Each point represents the mean \pm SEM. The asterisks indicate significantly different from respective control, $p<$ 0.05 .

of $1.7 \pm 1.3 \%$ ). Similar results were obtained at an identified cholinergic synapse of the buccal ganglion (Fig. 1B). In seven preparations, the inhibitory postsynaptic current (IPSC) induced in the postsynaptic neuron by a presynaptic action potential was increased $176.2 \pm 36.6 \%$ above control in presence of $3: 3 \mathrm{ASW}$ solution $(t=-3.55 ; p<0.05)$. The same synaptic current was not significantly altered by 2:1 ASW solution (increase of 6.0 $\pm 6.4 \%)$.

Finally, the modified ASW solutions were.tested at the monosynaptic connection between LE sensory neurons and LFS or L7 motor neurons. Because this synapse undergoes prominent depression with repeated activations, it was necessary to establish a control curve of the EPSP decline. Action potentials were triggered by intracellular stimulation of sensory neurons every
5 min. $\Lambda$ fter the fourth stimulation, the normal perfusion solution was either left as is $(n=12)$ or replaced by the $3: 3(n=$ 7) or 2:1 $(n=4)$ ASW solutions. We found that perfusion of the 3:3 ASW solution induced a clear increase in EPSP amplitude when compared to the control solution (Fig. 1C). The EPSP amplitudes were significantly increased for the fifth through eighth stimulations $(t=-3.08,-2.45,-2.63,-3.44 ; p<0.05)$. The mean increase was $176.3 \pm 32.6 \%$ above control. The $2: 1 \mathrm{ASW}$ was found to induce only a small nonsignificant decrease $(-11.4$ $\pm 1.9 \%$ ). The solutions had no apparent effect on time to peak and duration of monosynaptic EPSPs.

\section{Effects of modified ASWS on compound EPSPS evoked by siphon nerve stimulation}

Having established that the 2:1 ASW did not have any important effect on monosynaptic transmission, we then investigated the effect of this solution on the compound EPSPs induced in the GSW reflex motor neurons by siphon nerve stimulation. We first verified that the changes in perfusion solutions were not associated with an infiltration of the modified ASW into the suction electrodes thereby possibly changing the number of sensory fibers recruited by the nerve stimulation. This was tested with an addition of the vital dye fast green (10\%) into the perfusion solution. We found that the tight-fitting suction electrodes did not allow any observable changes in their internal solutions after perfusion of fast green for $30 \mathrm{~min}$ (as examined through a microscope). As an additional control, we subsequently performed experiments using a modified experimental chamber that allowed the siphon nerve to exit the main chamber through a Vaseline-sealed aperture; the nerve was therefore stimulated by a suction electrode that was always exposed to normal ASW in the secondary chamber. We found that the $2: 1$ ASW affected the compound EPSPs to the same extent in the two types of experimental setup. The finding that the same results were also obtained with tactile stimulation of the siphon skin (see below) indicates that a modification of the number of sensory axons recruited by the suction electrode stimulation in 2:1 ASW was not a problem under our experimental conditions.

Compound EPSPs were elicited every $5 \mathrm{~min}$. Their peak amplitudes were between 10 and $30 \mathrm{mV}$ with the postsynaptic neurons hyperpolarized to about $30 \mathrm{mV}$ below their resting potential (usually close to $-50 \mathrm{mV}$; experiments were thus performed with the neurons polarized to $-80 \mathrm{mV}$ ). These values correspond to a moderate stimulation of the network (Byrne et al., 1978). Two to five control EPSPs were first recorded. When the normal ASW was replaced by $2: 1$ ASW (Fig. $2 A$ ) a $78.3+$ $4.2 \%$ decrease in compound EPSP area was observed (measured with the SPIKE data analysis software) $(n=10 ; t=2.94 ; p<$ 0.01 ). Figure $2 A$ also illustrates the time course of the effect and shows that it was reversible: reintroduction of normal ASW allowed recovery of the response within $30 \mathrm{~min}$. The reference level used to calculate the effect of the treatment was the average of the last control EPSP before solution change and the last EPSP recorded during the washout period. In another set of experiments $(n=7)$, perfusion of the $3: 3$ ASW was also associated with a decrease in compound EPSP area recorded in motoneurons. The decrease was smaller than that induced by the 2:1 solution: a significant decrease of $64.9 \pm 6.2 \%$ was observed $(t=9.09 ; p<0.01)$.

To verify if the $2: 1$ ASW was able to prevent excitatory interneurons from firing action potentials upon siphon afferent input, intracellular recordings were obtained in some of them. 
A

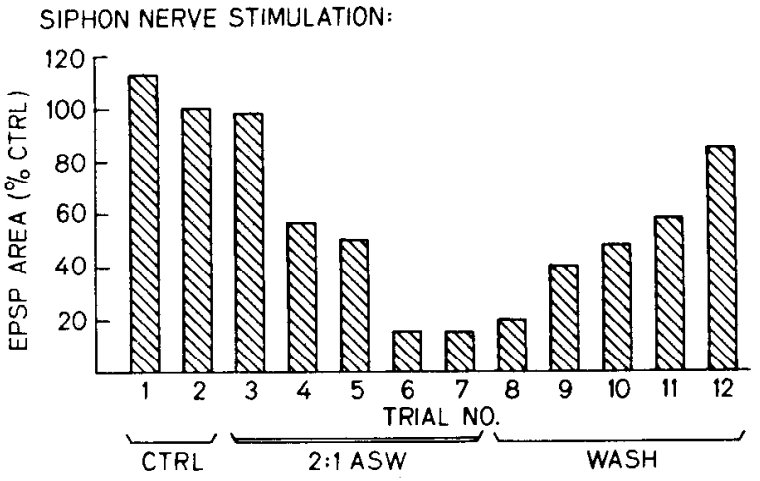

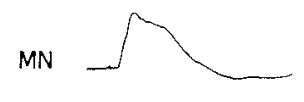

NORMAL ASW

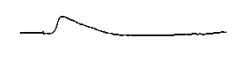

$2: 1$ ASW

B

SIPHON NERVE STIMULATION
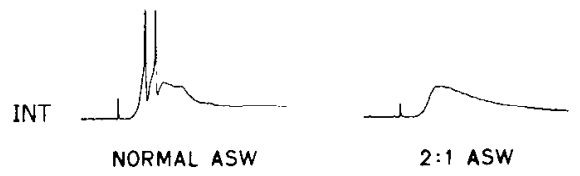

$2: 1$ ASW

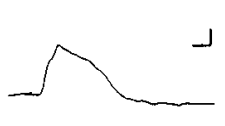

WASH

C

TACTILE SIPHON STIMULATION:
MN Mnvemom

NORMAL ASW

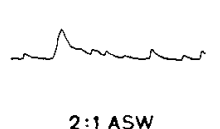

2:1 ASW

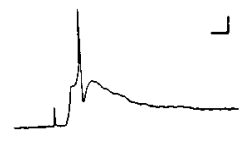

WASH

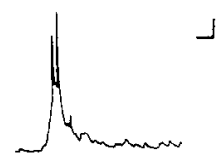

WASH
Figure 2. Effect of modified ASWs on compound EPSPs and excitatory interneurons. Compound EPSPs were evoked in motoneurons (polarized to $-80 \mathrm{mV}$ ) upon stimulation of the siphon nerve. Interstimuli interval was $5 \mathrm{~min}$. $A$, Bar graph represents EPSP area of a representative experiment. Perfusion with the 2:1 ASW after the second control (CTRL) induced an important decrease of the area of EPSPs recorded in the motoneuron $(M N$, traces below). The effect was reversible upon reintroduction of the normal ASW (WASH). Voltage traces correspond to EPSPs 2, 7, and 12 of the bar graph. Calibration: $8 \mathrm{mV}, 40 \mathrm{msec} . B$, Intracellular recordings were also performed in identified excitatory interneurons $(I N T)$. These are sample traces from a representative experiment. The neuron was not polarized below its resting potential; siphon nerve stimulation produced one to three action potentials in the interneuron. In 2:1 ASW, all firing was prevented. The effect was reversible. Calibration: $9 \mathrm{mV}, 40 \mathrm{msec}$. $C$, The same protocol was also performed in experiments where tactile stimulation of the siphon replaced siphon nerve stimulation. Perfusion with the 2:1 ASW again induced an important decrease of compound EPSPs area. Calibration: $10 \mathrm{mV}, 200 \mathrm{msec}$.

The recordings were made in the vicinity of the L14 ink gland motoneurons, where the L34 excitatory interneurons have previously been identified (Frost, 1987). These interneurons receive monosynaptic EPSPs from the LE sensory neurons, and directly synapse upon LFS motoneurons. The interneurons were identified by these connections. They were not polarized below their resting potential $(-55 \mathrm{mV})$. It was found that in normal ASW, at a stimulation level sufficient to induce compound EPSPs between 20 and $40 \mathrm{mV}$ in LFS motoneurons, siphon nerve stimulation usually produced one to three action potentials in these interneurons. Sample recordings in Figure $2 B$ illustrate that during pcrfusion of 2:1 ASW, the neurons always remaincd

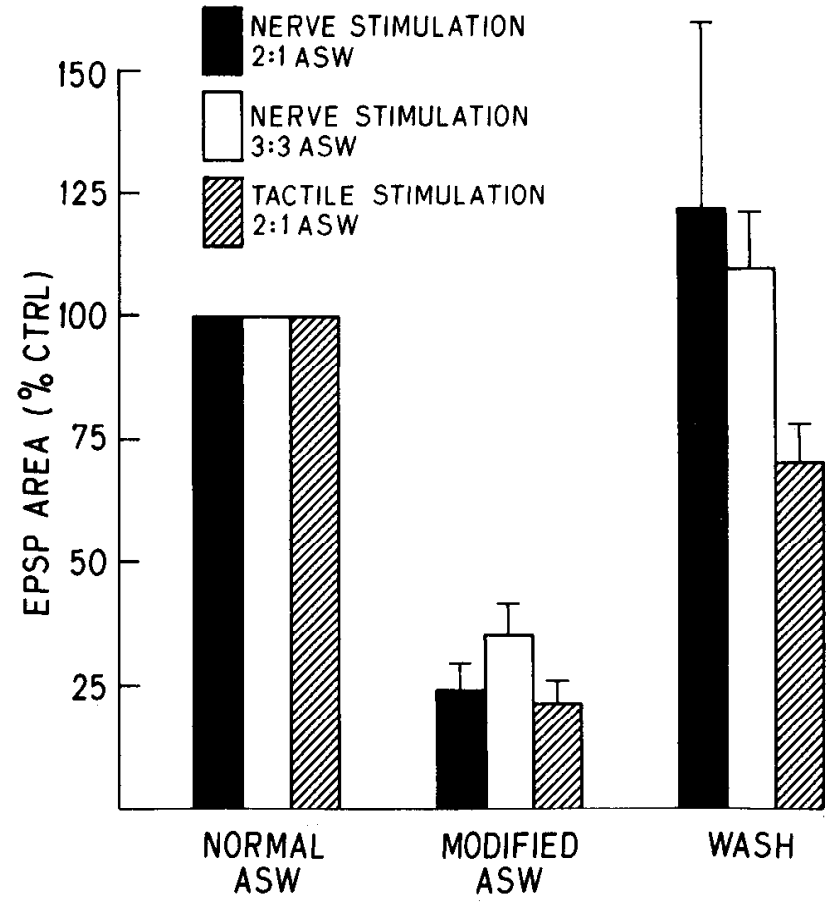

Figure 3. Effect of modified ASWs on compound EPSPs. The bar graph summarizes the effect of the 2:1 and 3:3 ASW media, which contain high concentrations of divalent cations, on compound EPSPs evoked in motoneurons upon siphon nerve stimulation (solid bars, $n=10$; open bars, $n=7$ ) or tactile stimulation of the siphon (hatched bars, $n=8$ ). The decreases in EPSP area induced by the modified ASWs were reversible. In some cases, the recovery was incomplete when tactile stimulation was used. The $100 \%$ level represents the last control recorded in normal ASW. The second group of bars represents the relative area of the last recording made in modified ASW, while the third group of bars corresponds to the last recording of the washout period. Error bars represent SEM.

below action potential threshold. Similar effects were observed in three other preparations $(n=4)$; these effects were reversible upon reintroduction of normal ASW.

\section{Effects of modified ASW on compound EPSPS evoked by tactile stimulation of the siphon}

The effect of the 2:1 solution on compound EPSPs in motoneurons was also evaluated by substituting tactile stimulation of the siphon for siphon nerve stimulation. This was thought to be important since electrical stimulation of the siphon nerve, although more reliable and controllable, could recruit a population of sensory fibers and interneurons not really equivalent to that recruited by tactile stimulation of the siphon skin. The tactile stimulation was adjusted to evoke EPSPs that were comparable to those obtained by electrical stimulation of the siphon nerve (peak amplitude, between 10 and $40 \mathrm{mV}$ ). Perfusion of the 2:1 ASW induced a 75.4 $\pm 4.0 \%$ decrease of compound EPSP area in the eight preparations tested $(t=4.00 ; p<0.01)$ (Fig. $2 C$ ). The effect was thus quantitatively the same as that observed with compound EPSPs induced by siphon nerve stimulation. These results are summarized in Figure 3, which also illustrates the extent of recovery in the washout period.

\section{Polysynaptic EPSPs evoked by single action potentials in sensory neurons of the reflex}

The above results suggested that polysynaptic connections account for a considerable proportion of the afferent input to the 


\section{ASW}

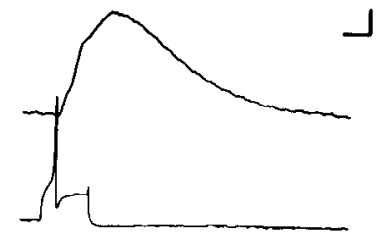

2:1 ASW

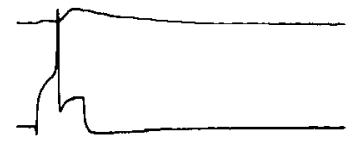

Figure 4. Multicomponent EPSPs to single action potentials in sensory neurons. An action potential (lower traces) was elicited in an LE sensory neuron and EPSPs recorded in a motoneuron (upper traces). In normal ASW, EPSPs frequently displayed multiple components. An example of such a polysynaptic response is illustrated. The two examples were successively recorded within the same experiment with an interstimuli interval of $5 \mathrm{~min}$. Perfusion with either $2: 1$ or $3: 3 \mathrm{ASW}$ always induced the rapid disappearance of the polysynaptic component of the EPSPs. Calibration: $9-15 \mathrm{mV}, 30 \mathrm{msec}$.

motoneurons. This conclusion is supported by the frequent observation that a single action potential in an LE sensory neuron can evoke multicomponent, polysynaptic EPSPs in gill and siphon motoneurons. An example of such responses is illustrated in Figure 4. These responses suggest the presence of excitatory interneurons interposed between sensory and motor neurons. We sampled a number of synapses between LE sensory neurons and gill or siphon motoneurons to get an estimate of the occurrence of such polysynaptic connections. We found that in 44 synapses tested (in 30 different preparations), 24 displayed polysynaptic EPSPs to single action potentials in the sensory neuron (54.5\%). The polysynaptic component of the EPSP was lost in all cases $(n=12)$ where the perfusion solution was changed to the $2: 1$ or $3: 3$ ASW solutions (Fig. 4).

\section{Selective modulation of the monosynaptic and polysynaptic components of compound EPSPS by 5-HT and SCP}

The importance of the polysynaptic pathway stresses the necessity to investigate the degree of plasticity this component of the GSW reflex may undergo. The neuromodulator 5-HT has becn shown to play a significant role in the facilitation of the monosynaptic connections between sensory and motor neurons of the GSW reflex (Brunelli et al., 1976; Clark and Kandel, 1984). The effect of this substance ( $5 \mu \mathrm{M}$, applied directly in the perfusion chamber) was tested on compound EPSPs evoked in motoneurons upon siphon nerve stimulation. We first determined in preliminary experiments that $5 \mu \mathrm{M}$ gave near the maximal effect; this result is similar to that obtained by M. Klein (personal communication) on synapses between sensory neurons and motoneurons in culture (maximal effect, around 10 $\mu \mathbf{M})$ and those of Simmons and Koester (1986) in another system. Experiments were performed either in normal ASW or in 2:1 ASW to estimate the respective effect of the treatment on the monosynaptic and polysynaptic components of the neural
A

NORMAL ASW :

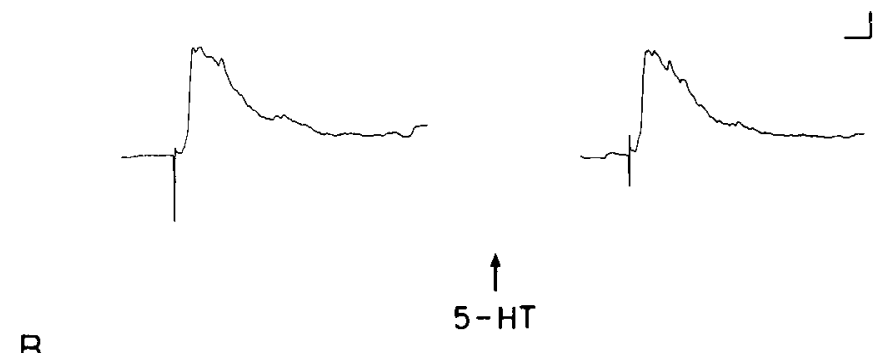

2:1 ASW:

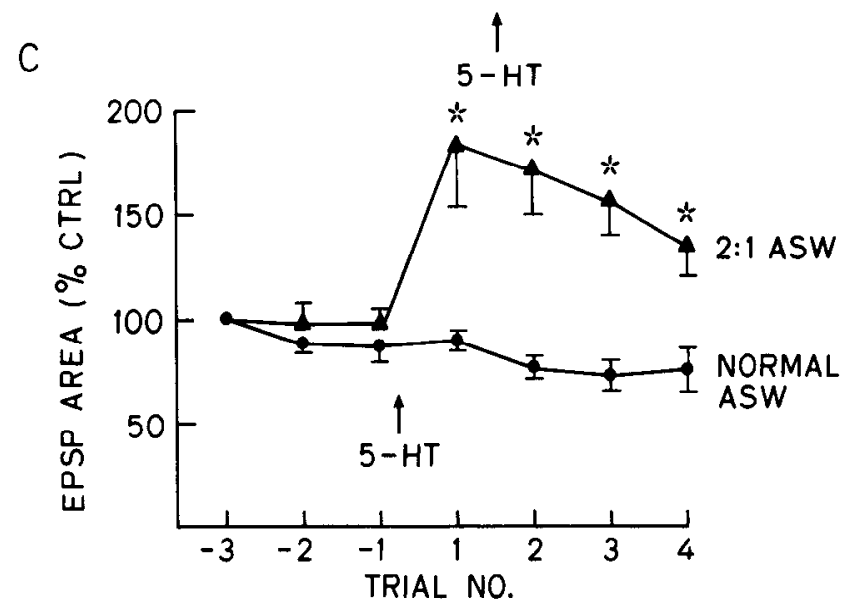

Figure 5. Effect of 5-HT on compound EPSPs. Compound EPSPs were evoked in motoneurons upon stimulation of the siphon nerve. Interstimuli interval was $1 \mathrm{~min}$. Experiments were performed either in normal ASW or in 2:1 ASW. Approximately eight control responses were taken before the direct application of 5-HT in the bath to a final concentration of $5 \mu \mathrm{M}$. $A$, In normal ASW, application of 5-HT had little effect on compound EPSPs. The last control and first test EPSP of a representative experiment are shown. Calibration: $8 \mathrm{mV}, 60 \mathrm{msec} . B$, In 2:1 ASW, where polysynaptic transmission is greatly reduced, 5-HT was found to induce a significant potentiation of EPSP area. Calibration: $6 \mathrm{mV}, 100 \mathrm{msec}$. $C$, The graph illustrates the last three controls and the following four test EPSPs of all experiments. EPSP areas are presented relative to the first plotted control $(-3)$. Each point represents the mean $\pm \operatorname{SEM}(n=5)$. The asterisks indicate significantly different from the last control $(-1), p<0.05$.

network. It was assumed that effects observed under 2:1 ASW could be largely attributed to alterations of monosynaptic transmission while effects observed under normal ASW reflected a summation of actions on both monosynaptic and polysynaptic transmission.

Two separate series of experiments were carried out: one in ASW, the other in 2:1 ASW. This was necessary since we found in pilot studies that with repeated exposures to the drug the physiological effects were reduced. The siphon nerve was stimulated every minute; after about eight stimuli, when the EPSPs had stabilized, the drug was applied in the bath. The following four responses were compared to the last control response. Application of 5-HT ( $5 \mu \mathrm{M})$ on compound EPSPs recorded in nor- 
A

NORMAL ASW:

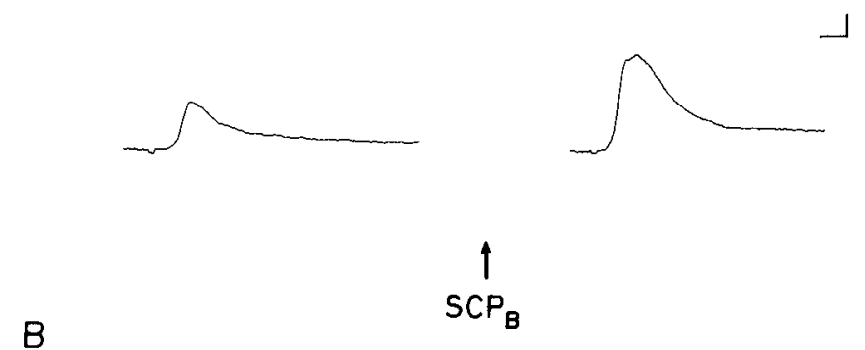

$2: 1$ ASW :

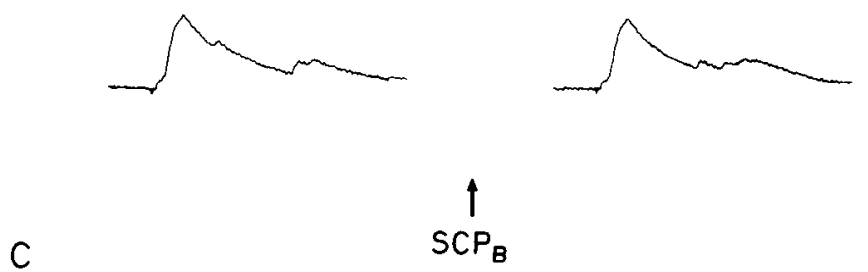

C

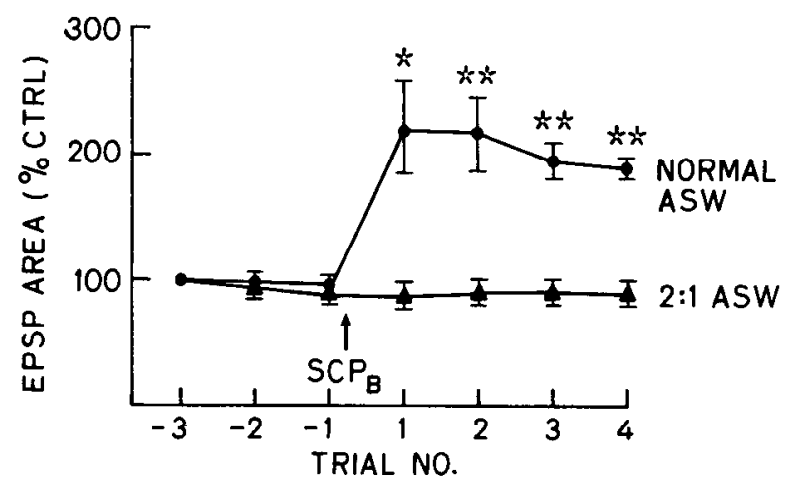

Figure 6. Effect of $\mathrm{SCP}_{\mathrm{B}}$ on compound EPSPs. Compound EPSPs were evoked in motoneurons upon stimulation of the siphon nerve. Interstimuli interval was $1 \mathrm{~min}$. Experiments were performed either in normal ASW or in 2:1 ASW. Approximately eight control responses were taken before the direct application of $\mathrm{SCP}_{\mathrm{B}}$ in the bath to a final concentration of $1 \mu \mathrm{M}$. A, In normal ASW, application of $\mathrm{SCP}_{\mathrm{B}}$ induced a significant increase in EPSP area. The last control and first test response of a representative experiment are shown. Calibration: $4 \mathrm{mV}, 70 \mathrm{msec}$. $B$, In 2:1 ASW, where polysynaptic transmission is grcatly reduced, $\mathrm{SCP}_{\mathrm{B}}$ was found to have little effect on compound EPSPs. Calibration: $5 \mathrm{mV}, 80 \mathrm{msec}$. $C$, The graph illustrates the last three controls and the following four test EPSPs of all experiments. EPSP areas are presented relative to the first plotted control $(-3)$. Each point represents the mean \pm SEM $(n=5)$. The asterisks indicate significantly different from the last control $(-1):^{*}, p<0.05 ;{ }^{* *}, p<0.01$.

mal ASW had no significant effect, with a $2.0 \pm 7.2 \%$ increase in EPSP area measured for the first test response $(n=5)$ (Fig. $5 A, C)$. At higher doses (10 and $50 \mu \mathrm{M})$, inhibitory effects were sometimes observed (results not shown; see also Fitzgerald and Carew, 1991). In 2:1 ASW (Fig. 5B,C), 5-HT induced an 87.1 $\pm 22.7 \%$ increase in the EPSP area of the first test EPSP $(n=$ $5 ; t=-3.04 ; p<0.05)$. The three subsequent responses were also significantly increased $(t=-2.97,-3.06,-2.44 ; p<0.05)$ (Fig. 5C). A net potentiation of synaptic transmission by 5 -HT was thus only produced on the monosynaptic component of compound FPSPs.

The neuropeptide $\mathrm{SCP}_{\mathrm{B}}$ is present in the CNS of Aplysia and is another possible modulator involved in sensitization of the
A

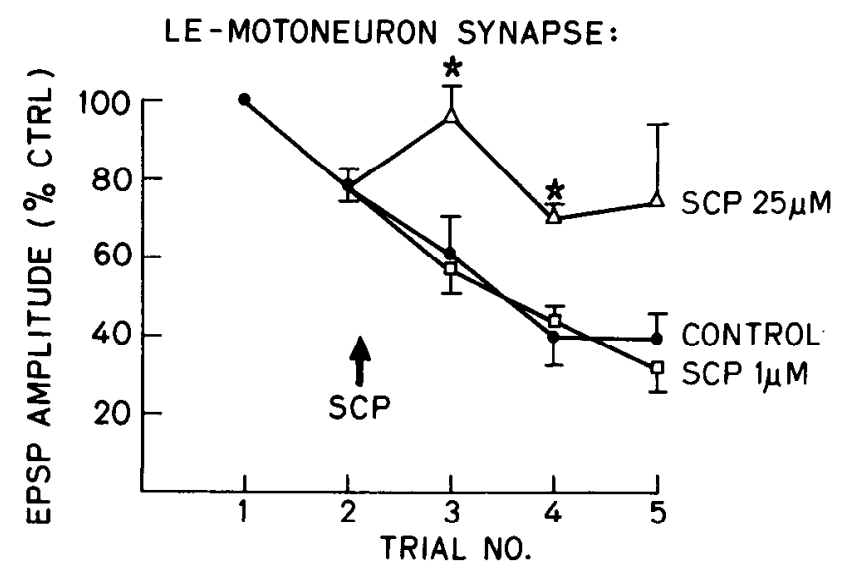

B

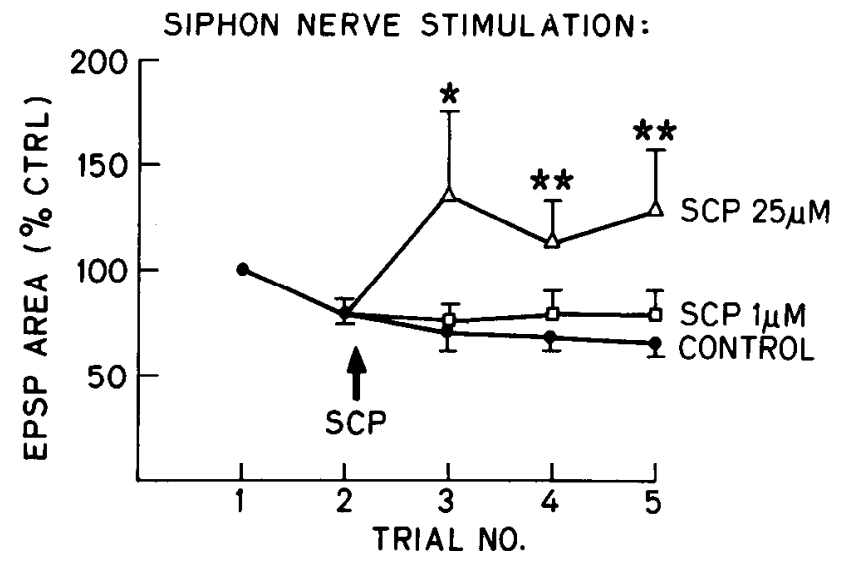

Figure 7. Effect of a higher concentration of $\mathrm{SCP}_{\mathrm{B}}$ on monosynaptic transmission. The effect of $25 \mu \mathrm{M} \mathrm{SCP}$ on monosynaptic transmission was assessed on nondepressed connections. All experiments were performed in 2:1 ASW. Interstimuli interval was $1 \mathrm{~min}$. $A$, EPSPs were evoked in motoneurons by the threshold stimulation of an LE neuron. After two control responses, $\mathrm{SCP}_{\mathrm{B}}$ was added in the bath to a final concentration of either $1 \mu \mathrm{M}(n=4)$ or $25 \mu \mathrm{M}(n=4)$, and four test EPSPs were recorded. In the control condition $(n-5)$, no $\mathrm{SCP}_{\mathrm{B}}$ was added. $\mathrm{SCP}_{\mathrm{B}}$ at $25 \mu \mathrm{M}$ induced a significant increase in EPSP amplitudes relative to their respective controls. No effect was observed when $1 \mu \mathrm{M}$ was used. $B$, In another set of experiments, compound EPSPs were evoked in motoneurons by siphon nerve stimulation. At $25 \mu \mathrm{M}(n=4)$, $\mathrm{SCP}_{\mathrm{B}}$ induced an increase in EPSP areas relative to their untreated controls $(n=9)$. No effect was observed at $1 \mu \mathrm{M} \mathrm{SCP}_{\mathrm{B}}(n=4)$. The asterisks indicate significantly different from respective controls: ${ }^{*}, p<$ $0.05 ;{ }^{* *}, p<0.01$.

withdrawal reflex (Abrams et al., 1984; Lloyd et al., 1985). Its effect ( $1 \mu \mathrm{M}$, applied in the bath) was also evaluated on compound EPSPs in two separate studies, either in normal ASW or in 2:1 ASW. As was the case for 5-HT, we found that repeated exposures to $\mathrm{SCP}_{\mathrm{B}}$ reduce its subsequent physiological effects on neurons (see also Abrams et al., 1984).

Application of the peptide $(1 \mu \mathrm{M})$ in the presence of normal ASW (Fig. $6 A, C$ ) produced a significant potentiation. A mean increase of $121.3 \pm 3.4 \%$ above control was found for the first test response in five preparations $(t=-3.16 ; p<0.05)$. The next three EPSPs were also significantly increased $(t=-4.75$, $-5.74,-10.14 ; p<0.01$ ) (Fig. 6C). By contrast, the effect of $1 \mu \mathrm{M} \mathrm{SCP}$ B was markedly different in 2:1 ASW ( $n=5$; Fig. $6 B, C$ ). The procedure failed to modify the compound EPSP area: a $2.6 \pm 4.4 \%$ decrease was found for the first test response. A significant potentiation of synaptic transmission by $\mathrm{SCP}_{\mathrm{B}}$ was 

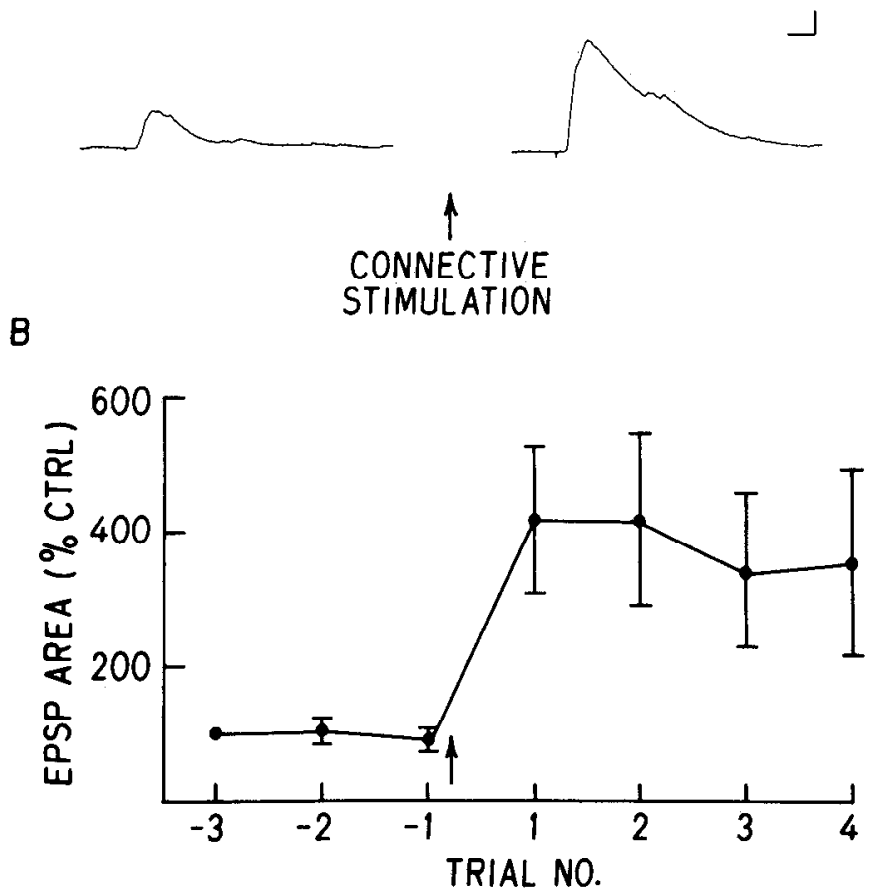

Figure 8. Effect of left connective stimulation on compound EPSPs. Compound EPSPs were evoked in motoneurons by siphon nerve stimulation. Experiments were performed in normal ASW. Interstimuli interval was $1 \mathrm{~min}$. Following approximately eight controls, the left connective was stimulated for $5 \mathrm{sec}(8 \mathrm{~Hz}$, each pulse $5 \mathrm{~V}, 3 \mathrm{msec})$. $A$, The traces illustrate the last control EPSP $(B,-1)$ and first test EPSP $(1)$ of a representative experiment. Connective stimulation induced a large increase in compound EPSP area. Calibration: $10 \mathrm{mV}, 80 \mathrm{msec} . B$. The last three control EPSPs and first four test EPSPs of all experiments are summarized. Each point represents the mean \pm SEM $(n=5)$.

thus produced only on the polysynaptic component of the neural network underlying the GSW reflex.

The failure of $\mathrm{SCP}_{\mathrm{B}}$ to potentiate monosynaptic transmission was surprising in the light of past findings (Abrams et al., 1984; Schacher et al., 1990). In those studies, however, doses of 25 $\mu \mathrm{M}$ were used. The effects of 1 and $25 \mu \mathrm{MSCP}$, were thus verified directly at LE-L7 or LE-LFS synapses in the presence of 2:1 ASW. In these experiments, only two control responses were taken before application of $\mathrm{SCP}_{\mathrm{B}}$ in order to allow the drug effect to be tested on nondepressed connections; it has been reported that $\mathrm{SCP}_{\mathrm{B}}$ is more effective at nondepressed EPSPs (Schacher et al., 1990). After the two control EPSPs, three further test EPSPs were evoked following application of either $1 \mu \mathrm{M}(n=$ 4) or $25 \mu \mathrm{M}(n=4) \mathrm{SCP}_{\mathrm{B}}$. In five other experiments, no treatment was effected and the control decline assessed (Fig. 7A). As expected from the lack of effect of $1 \mu \mathrm{M}$ SCP on compound EPSPs recorded in 2:1 ASW, this concentration was found to have no effect on monosynaptic connections tested directly between LE and L7 or LFS neurons of the reflex (Fig. 7A). At a concentration of $25 \mu \mathrm{M}$, however, a clear potentiation of these synapses was noted (Fig. $7 \mathrm{~A}$ ). Both the first and second EPSPs following $\mathrm{SCP}_{\mathrm{B}}$ application were significantly higher than their respective control responses $(t=-2.89,-3.03 ; p<0.05)$, with a mean increase of $33.5 \pm 2.6 \%$. This concentration, unlike $1 \mu \mathrm{M}$ (Figs. $6 C, 7 B$ ) was also found to potentiate compound EPSPs evoked by siphon nerve stimulation in 2:1 ASW (Fig. 7B). A significant difference could be observed between the first, second, and third EPSPs following application of $25 \mu \mathrm{M} \mathrm{SCP}{ }_{\mathrm{B}}(n=4)$ and their respective untreated controls $(n=9)(\mathrm{t}=-2.42,-3.19,-3.21$; $p<0.05,0.01$, and 0.01 , respectively). The mean increase of the area for the third to fifth trials, relative to the control condition, was $57.4 \pm 5.6 \%$. Application of $1 \mu \mathrm{M} \mathrm{SCP}_{\mathrm{B}}(n=4)$ within such a protocol again failed to alter compound EPSPs significantly (Fig. $7 B$ ).

\section{Potentiation of compound EPSPs by left connective stimulation}

The potentiation of compound EPSPs was further studied by replacing application of neuromodulatory agents by left pleuroabdominal connective stimulation, a procedure that is thought to mimic sensitization of the GSW reflex by tail or head stimulation (Castellucci et al., 1970). This treatment was only carried out in normal ASW because perfusion of the 2:1 solution would lead to uncoupling of the facilitating interneurons, thereby preventing a good evaluation of the effect of these facilitating interneurons on compound EPSPs. The same protocol used to study the effect of neuromodulator application was used except that connective stimulation replaced drug application. In normal ASW, it was thus found that connective stimulation (one $5 \mathrm{sec}$ train, $8 \mathrm{~Hz}$, each pulse $5 \mathrm{~V}, 3 \mathrm{msec}$ ) induced an increase of $333.2 \pm 102.9 \%$ of compound EPSP area for the first test response $(n=5 ; t=-3.09 ; p<0.05)$ (Fig. $8 A, B)$.

\section{Polysynaptic EPSPs evoked by single action potentials in $L E$ sensory neurons: potentiation by left connective stimulation and tetanic stimulation}

The possibility that much of the potentiation of compound EPSPs by left connective stimulation results from increased transmission at the level of polysynaptic connections was investigated by monitoring the effect of left connective stimulation on EPSPs evoked in motoneurons by single action potentials in LE sensory neurons. We hypothesized that this facilitation protocol should promote the recruitment of excitatory interneurons by single action potentials in the sensory neurons. We found that left connective stimulation induced a considerable increase in the weight of the polysynaptic component of the responses (Fig. $9 A$ ). In many cases, a connection that was monosynaptic in control trials recruited polysynaptic components following connective stimulation. Such effects were observed in six out of nine synapses tested (in five preparations). The average increase in EPSP area for the nine connections was $733.6 \pm 368.5 \%(t$ $=-2.59 ; p<0.05$ ).

To explore further the role of the polysynaptic component of the reflex, we examined posttetanic potentiation in the LE sensory neurons. Posttetanic potentiation is another form of plasticity demonstrated by some synapses of the withdrawal reflex. An action potential was elicited every minute in an LE neuron. After the second EPSP was evoked in a motoneuron, a brief tetanic stimulation was applied to the sensory neuron (three short $8 \mathrm{~Hz}$ trains of $2 \mathrm{sec}$, separated by an interval of $1 \mathrm{sec}$ ). This protocol induced the appearance of a polysynaptic component in the evoked EPSPs or increased its importance in synapses where a polysynaptic component was already present (Fig. $9 B$ ) in seven out of nine synapses tested (in four preparations). The average increase in EPSP area for the nine connections was $305.5 \pm 123.8(t=-3.19 ; p<0.05)$. These results further illustrate the significant contribution of polysynaptic connections in the mediation of the GSW reflex. 


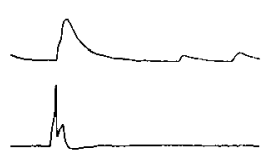

1

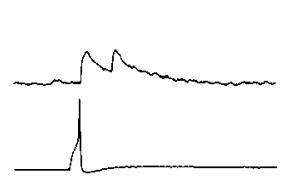

1

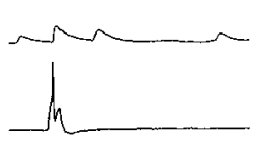

2

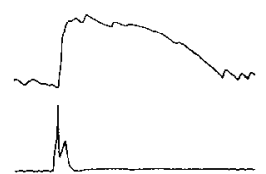

3

CONNECTIVE

STIMULATION

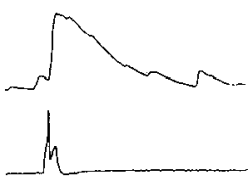

4

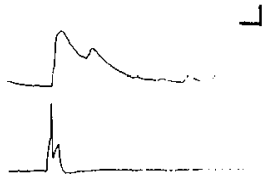

5

B

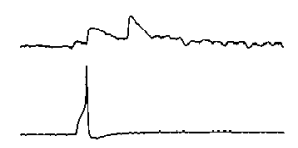

2

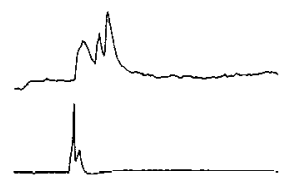

3

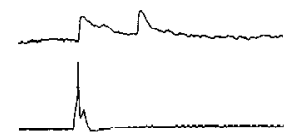

4

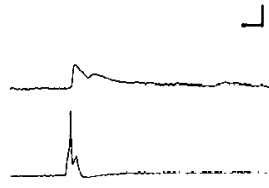

5

TETANIC

STIMULATION

Figure 9. Effect of connective stimulation and tetanic stimulation upon LE-motoneuron EPSPs. Experiments were performed in normal ASW. EPSPs (upper traces) were evoked in motoneurons by threshold stimulation of LE sensory neurons (lower traces). A, Two to three control EPSPs were recorded before stimulation of the left connective for $5 \mathrm{sec}(8 \mathrm{~Hz}$, each pulse $5 \mathrm{~V}, 3 \mathrm{msec})$. This treatment resulted in an important potentiation of EPSPs, often associated with the appearance of multiple, polysynaptic components to the EPSPs. The records of a representative experiment are presented. Traces were recorded sequentially. Interstimuli interval was 1 min. Calibration: $10-20 \mathrm{mV}, 80 \mathrm{msec}$. B, The same protocol was repeated in another set of experiments except that tetanic stimulation (three $2 \mathrm{sec}$ trains of $8 \mathrm{~Hz}$, intertrain interval of 1 sec) of the presynaptic LE neuron replaced connective stimulation. This protocol also induced an important potentiation of EPSPs, again often associated with the appearance or potentiation of polysynaptic components of the EPSPs. A representative experiment is illustrated. Calibration: 10-20 mV, $60 \mathrm{msec}$.

\section{Discussion}

Importance of the polysynaptic pathway of the GSW neuronal network

Despite the fact that excitatory and inhibitory interneurons have been described in the neural circuit of the GSW reflex (Hawkins et al., 1981a; Frost et al., 1988), most of the studies so far have focused on the monosynaptic connection between one group of sensory mechanoreceptors (LE cluster) and the motor neurons of the circuit. Recent studies, however, suggest that the contribution of the interneurons may be important. They may indeed play a role in the mediation of both the amplitude and duration of the gill or siphon contraction (Frost et al., 1991). A similar conclusion has also been rcached by Byrne and his colleagues (White et al., 1991) for the tail withdrawal reflex. The possible importance of some types of inhibitory processes within the interneuronal network for the short-term inhibition of the GSW reflex has also been stressed by Carew and his colleagues (Fitzgerald and Carew, 1991; Wright et al., 1991). If such polysynaptic connections are important for the mediation of the reflex, they might also be a crucial site of plasticity. Our studies were designed to determine the importance of the polysynaptic pathway in the withdrawal reflex. They confirm and broaden the conclusions of the study of Byrne et al. (1978), which suggested that approximately $40 \%$ of compound EPSPs could be attributed to the polysynaptic pathway. We took care to verify that the modified ASW we used to reduce the interneuronal contribution did not alter monosynaptic transmission. At three different types of synapses, we found that one of the solutions tested (3:3 ASW) markedly increased synaptic transmission, while the other $(2: 1$
ASW) was without important effect (Fig. $1 A-C$ ). Since Byrne et al. (1978) used a 3:3 ASW solution, this may explain why they underestimated the contribution of the polysynaptic pathway. With the $2: 1$ ASW, we found that $78.3 \%$ of the compound EPSP (area) evoked in motoneurons of the reflex by siphon nerve stimulation was lost (Figs. $2 A, 3$ ). The same conclusion was reached when siphon skin stimulation was substituted for siphon nerve stimulation (Fig. $2 C$ ). Since, under our conditions, monosynaptic transmission was not affected, we believe that the response diminution is due to the functional uncoupling of interneurons in the GSW reflex network. We have recorded from a subset of excitatory interneurons (L34 cluster) and found that action potential firing upon siphon nerve stimulation was completely prevented in 2:1 ASW (Fig. 2B). We conclude that the polysynaptic pathway is quantitatively very important for the mediation of the GSW reflex (Fig. 10A). Another observation that indicates the significant weight of the interneuronal component in the reflex is that at least $54.6 \%$ of our sampled synapses ( 24 of 44 synapses in 30 preparations) between LE sensory neurons and motoneurons of the GSW reflex included a polysynaptic component (Fig. 4). Again, it should be noted that this is almost certainly an underestimation, as convergence of more than one sensory neuron on a given interneuron is probably often necessary for triggering an action potential. These interneurons would not be recruited by single action potentials in sensory neurons. The fact that in many cases a single action potential in a sensory neuron is sufficient to reveal the presence of interneurons is indicative of very strong synapses between sensory neurons and interneurons. These excitatory interneu- 
A

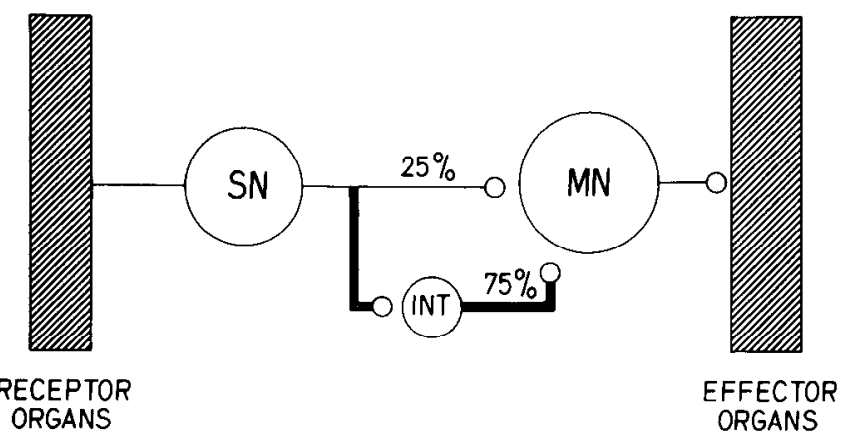

B

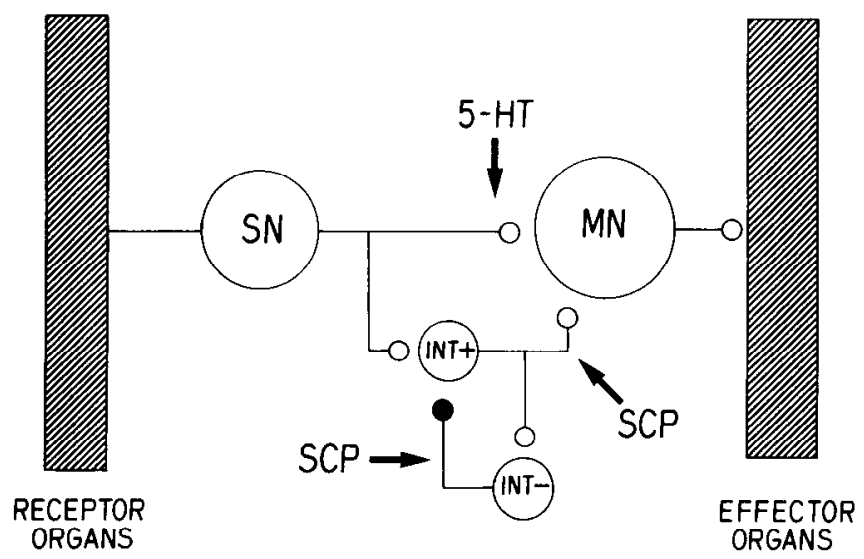

Figure 10. Summary diagram. A, A simplified representation of the GSW refiex circuit. Results presented in this article suggest that approximately $25 \%$ of the afferent input to motoneurons, following siphon stimulation, may be mediated by monosynaptic connections between sensory and motor neurons. The remaining $75 \%$ would be mediated through interneurons interposed between sensory and motor neurons. $S N$, sensory neurons; $M N$, motor neurons; $I N T$, interneurons. $B$, The monosynaptic and polysynaptic components of the neuronal network underlying the GSW reflex may be differentially modulated: 5-HT appears to act preferentially on the monosynaptic pathway, while $\mathrm{SCP}_{\mathrm{B}}$ appears to act preferentially on the polysynaptic pathway. This latter effect may be through a direct action on excitatory interneurons $\left(I N T^{+}\right)$, or through a modification of inhibitory interneuronal transmission $\left(I N T^{-}\right)$.

rons may be thought of as mediating an amplification of the sensory message to the motoneurons of the reflex.

Plasticity within the polysynaptic component of the GSW neuronal network

The importance of the polysynaptic network suggests the possibility of it being an additional site of plasticity involved in learning-associated modifications of the GSW reflex. It has been shown, for example, that some identified interneurons can undergo posttetanic potentiation (Hawkins et al., 1981b; Frost et al., 1988) and that recurrent inhibition between L30 and L29 interneurons is reduced during behavioral sensitization of the reflex (Frost et al., 1988). In this article, we have explored further the importance of plasticity in the polysynaptic pathway. First, we looked at the effect of two facilitating transmitters of the reflex: 5-HT and $\mathrm{SCP}_{\mathrm{B}}$.

The relative effect of these substances on transmission within the monosynaptic and the polysynaptic component of the neuronal network was estimated by comparing their effect on com- pound EPSPs generated in motoneurons by siphon nerve stimulation in 2:1 ASW or in normal ASW. We assumed that the effects observed under 2:1 ASW could be largely attributed to the monosynaptic component of the network. We found with this procedure a differential modulation of the monosynaptic and polysynaptic components of the GSW network (Fig. 10B). Exposure to 5-HT $(5 \mu \mathrm{M})$ had a much greater effect on transmission in the monosynaptic pathway than in the polysynaptic pathway (Fig. 5). By contrast, the specificity of $\mathrm{SCP}_{\mathrm{B}}$ was found to be opposite (Figs. 6, 7). Its effect $(1 \mu \mathrm{M})$ was much greater on the polysynaptic than on the monosynaptic component of compound EPSPs. A considerable increase of $\mathrm{SCP}_{\mathrm{B}}$ concentration $(25 \mu \mathrm{M})$ was required to show that the peptide could nonetheless potentiate transmission at the level of monosynaptic connections between sensory and motor neurons (Fig. 7), as previously reported (Abrams et al., 1984; Schacher et al., 1990).

The magnitude of the effect of 5-HT on the monosynaptic component of compound EPSPs is in agreement with the values reported for the facilitation induced by this modulator at synapses between LE and LFS or L7 motoneurons (Clark and Kandel, 1984). If monosynaptic connections are responsible for approximately $25 \%$ (Figs. 2, 3) of compound EPSPs, an $87 \%$ (Fig. 5) increase in this component of the network should have resulted in an approximate $20 \%$ potentiation of the compound EPSP recorded in normal ASW, assuming that 5-HT had no effect on polysynaptic transmission. Only a $2 \%$ incrcase was found. It is possible that 5-HT not only fails to potentiate excitatory transmission in the polysynaptic pathway but actually decreases it. This hypothesis is similar to the suggestion made by Carew and his colleagues (Fitzgerald and Carew, 1991; Wright et al., 1991) that tail stimulation and 5-HT may activate transient inhibitory processes at the interneuronal level at the same time as potentiating monosynaptic transmission. A second possible explanation is the fact that the EPSPs, under control conditions, underwent a small but gradual depression. Because the drug effects were calculated in relation to the last control response before drug application, irrespective of the spontaneous decrease, a small underestimation of the effect of the treatment may be expected.

The small effect of 5-HT on the compound EPSP in normal ASW is also in apparent contradiction with past findings that indicated that direct application of 5-HT to the abdominal ganglion could significantly potentiate gill contraction following tactile stimulation of the siphon in a semiintact preparation (Abrams et al., 1984). The report of the blockade of GSW reflex sensitization through tail stimulation by the 5-HT neurotoxin 5,7-dihydrotryptamine (Glanzman et al., 1989) might also be thought as incompatible with the small effect of 5-HT on compound EPSPs under normal ASW. These discrepancies could, however, be explained if one considers that 5-HT could also act at a stage later than transmitter release by the sensory neurons. It has been shown, for example, that 5-HT increases motoneuron basal firing rate, thereby inducing greater gill contractions for any given sensory input (Frost et al., 1988).

The potentiation of polysynaptic transmission by $\mathrm{SCP}_{\mathrm{B}}$ may possibly be explained as resulting from increased transmission at synapses between excitatory interneurons and motoneurons or, alternatively, from decreased transmission at synapscs bctween inhibitory interneurons and excitatory interneurons or motoneurons (Fig. 10B). An example of an inhibitory interneuron (L16 or L30 cluster) synapsing upon an excitatory interneuron (L29 cluster) has been reported (Hawkins et al., 1981a; 
Frost et al., 1988), but the importance of such connections in the normal mediation of the GSW reflex and its plasticity remains unexplored.

It is interesting to compare the control decline curves of LEmotoneuron synapses and compound EPSPs recorded in 2:1 ASW as presented in Figure 7. One may note that the nerveevoked EPSP, which is thought to be largely monosynaptic, does not depress as much as the LE-motoneuron synapse. Although we cannot provide a definitive explanation for this discrepancy, it should be realized that siphon nerve stimulation may recruit sensory neurons from many different clusters in addition to the LE cluster. It is very possible that sensory neurons from other clusters do not develop the same type of depression. Such a heterogeneity among different identified clusters of sensory neurons has indeed been noted for the effects of neuromodulatory agents on $\mathrm{K}^{+}$currents determining action potential duration (Dubuc and Castellucci, 1991; see also Rosen et al., 1989). We are presently investigating this heterogeneity in terms of transmitter release.

The effect of left connective stimulation (which mimics sensitizing sensory input from the tail and head of the animal) on compound EPSPs induced by siphon nerve stimulation was also evaluated. A facilitation of $333.2 \%$ was observed (Fig. 8). Considering the important role of polysynaptic connections in compound EPSPs, it is clear that potentiation of monosynaptic connections alone could not explain the $333.2 \%$ potentiation observed after left connective stimulation. If one makes the assumption that $75 \%$ of the compound EPSP area is attributable to polysynaptic connections (Figs. 2, 3), then a potentiation of approximately $1400 \%$ of the monosynaptic component would be necessary to explain the observed effect. This value is much higher than the potentiations previously reported for monosynaptic connections after left connective stimulation (Castellucci and Kandel, 1976). Although it is possible that following left connective stimulation, the sensory neurons already recruited might display an increased number of action potentials for the same siphon nerve stimulation, this possibility is thought unlikely, as occasional recordings of LE neurons during siphon nerve stimulation revealed that the short-duration shock used always produced a single action potential in these cells. These data may be taken as further evidence for the crucial role of the polysynaptic pathway in the plasticity of the GSW reflex. It is also interesting to note that the threefold potentiation of compound EPSP area observed after left connective stimulation is very similar to the figures reported for the potentiation of monosynaptic EPSPs under similar conditions (Castellucci and Kandel, 1976). This would tend to argue that left connective stimulation induces a proportional potentiation in the mono- and polysynaptic component of the GSW reflex neuronal network. Although part of this synaptic facilitation may be produced by the release of endogenous 5-HT and $\mathrm{SCP}_{\mathrm{B}}$, it also appears very likely that other modulators may contribute. For example, at the level of the monosynaptic connections, the possibility that other modulators besides 5-HT participate in GSW reflex sensitization is supported by the demonstration that the facilitating interneurons L29, which contain neither 5-HT nor SCP peptides, are nonetheless able to potentiate monosynaptic connections between LE sensory cells and motoneurons of the reflex (Hawkins et al., 1981b; Hawkins and Schacher, 1989). Posttetanic potentiation might also play a significant role in facilitating transmission at any stage of the neuronal network (Hawkins et al., 1981b; Walters and Byrne, 1984, 1985; Frost et al., 1988).
Its actual importance in sensitization of the GSW reflex is not known.

More direct support for the involvement of polysynaptic pathways in the plasticity of the GSW reflex was obtained by showing (Fig. 9A) that left connective stimulation induces a considerable increase in the polysynaptic component of EPSPs induced in motoneurons by a single action potential in a LE sensory neuron. This could be due to the recruitment of additional excitatory interneurons by the sensory neuron and/or to an increased number of action potentials produced by the interneurons already recruited. Disinhibition or increased excitability of the excitatory interneurons may thus be involved, and may be an important mechanism of plasticity of the GSW reflex. In this regard, it is interesting to notice that posttetanic potentiation of LE neuron synapses induced an increased recruitment of excitatory interneurons (Fig. 9B). This shows directly that most LE neurons probably make synaptic connections with excitatory interneurons that produce feedforward excitation to motoneurons of the reflex. The increased recruitment of these interneurons is probably a crucial mechanism of potentiation within the GSW reflex neuronal network. The importance of such mechanisms will be evaluated directly by recording from identified excitatory and inhibitory interneurons such as those of the L29, L30, L34, and L35 clusters (Hawkins et al., 1981a; Frost, 1987; Frost et al., 1988) as well as others previously unidentified that we are characterizing.

In conclusion, the data presented here suggest that polysynaptic connections are responsible for a considerable proportion of the afferent input to motoneurons involved in the GSW reflex (Fig. 10A). Evidence is also presented that indicates that this polysynaptic neuronal network is a key site of plasticity for the reflex. Finally, differential modulation of the monosynaptic and the polysynaptic component of the network by the neuromodulators 5-HT and $\mathrm{SCP}_{\mathrm{B}}$ is apparent (Fig. 10B); differential effects of this type may be important for a fine regulation of the GSW reflex associated with more complex forms of learning and memory. This selectivity may be a general principle for a variety of neuromodulators of the reflex, and work is presently under way in our laboratory to test this hypothesis.

\section{References}

Abrams TW, Castellucci VF, Camardo JS, Kandel ER, Lloyd PE (1984) Two endogenous neuropeptides modulate the gill and siphon withdrawal reflex in Aplysia by presynaptic facilitation involving cAMPdependent closure of a serotonin-sensitive potassium channel. Proc Natl Acad Sci USA 81:7956-7960.

Baux G, Fossier P, Tauc L (1990) Histamine and FLRFamide regulate acetylcholine release at an identified synapse in Aplysia in opposite ways. J Physiol (Lond) 429:147-168.

Brunelli M, Castellucci VF, Kandel ER (1976) Synaptic facilitation and behavioral sensitization in Aplysia: possible role of serotonin and cAMP. Science 194:1178-1180.

Byrne JH, Castellucci VF, Kandel ER (1974) Receptive fields and response properties of mechanoreceptor neurons innervating siphon skin and mantle shelf in Aplysia. J Neurophysiol 37:1041-1064.

Byrne JH, Castellucci VF, Kandel ER (1978) Contribution of individual mechanoreceptor sensory neurons to defensive gill-withdrawal reflex in Aplysia. J Neurophysiol 41:418-431.

Castellucci VF, Kandel ER (1976) Presynaptic facilitation as a mechanism for behavioral sensitization in Aplysia. Science 194:1176-1178.

Castellucci VF, Pinsker H, Kupfermann I, Kandel ER (1970) Neuronal mechanisms of habituation and dishabituation of the gill-withdrawal reflex in Aplysia. Science 167:1745-1748.

Castellucci VF, Kandel ER, Schwartz JH, Wilson FD, Nairn AC, Greengard P (1980) Intracellular injection of the catalytic subunit of cyclic AMP-dependent protein kinase stimulates facilitation of transmitter 
release underlying behavioral sensitization in Aplysia. Proc Natl Acad Sci USA 77:7492-7496.

Castellucci VF, Nairn AC, Greengard P, Schwartz JH, Kandel ER (1982) Inhibitor of adenosine 3':5-monophosphate-dependent protein kinase blocks presynaptic facilitation in Aplysia. J Neurosci 2: 1673-1681.

Clark GA, Kandel ER (1984) Branch-specific heterosynaptic facilitation in Aplysia siphon sensory cells. Proc Natl Acad Sci USA 81: 2577-2581.

Colebrook E, Lukowiak K (1988) Learning by the Aplysia model system: lack of correlation between gill and gill motor neurone responses. J Exp Biol 139:411-429.

Dubuc B, Castellucci VF (1991) Receptive fields and properties of a new cluster of mechanoreceptor neurons innervating the mantle region and the branchial cavity of the marine mollusk Aplysia californica. J Exp Biol 156:315-334.

Fitzgerald K, Carew TJ (1991) Serotonin mimics tail shock in producing transient inhibition in the siphon withdrawal reflex of Aplysia. J Neurosci 11:2510-2518.

Frazier WT, Kandel ER, Kupfermann I, Waziri R, Coggeshall RE (1967) Morphological and functional properties of identified neurons in the abdominal ganglion of Aplysia californica. J Neurophysiol 30: 1288-1351.

Frost WN (1987) Mechanisms contributing to short- and long-term sensitization in Aplysia. PhD thesis, Columbia University.

Frost WN, Castellucci VF, Hawkins RD, Kandel ER (1985) Monosynaptic connections made by the sensory neurons of the gill- and siphon-withdrawal reflex in Aplysia participate in the storage of longterm memory for sensitization. Proc Natl Acad Sci USA 82:82668269 .

Frost WN, Clark GA, Kandel ER (1988) Parallel processing of shortterm memory for sensitization in Aplysia. J Neurobiol 19:297-334.

Frost WN, Wu LG, Lieb J (1991) Stimulation of the Aplysia siphon withdrawal reflex circuit: slow components of interneuronal synapses contribute to the mediation of reflex duration. Soc Neurosci Abstr 17:1390.

Gardner D (1971) Bilateral symmetry and interneuronal organization in the buccal ganglia of Aplysia. Science 173:550-553.

Glanzman DL, Mackey SL, Hawkins RD, Dyke AM, Lloyd PE, Kandel ER (1989) Depletion of serotonin in the nervous system of Aplysia reduces the behavioral enhancement of gill withdrawal as well as the heterosynaptic facilitation produced by tail shock. J Neurosci 9:42004213.

Hawkins RD, Schacher S (1989) Identified facilitator neurons L29 and L28 are excited by cutaneous stimuli used in dishabituation, sensitization, and classical conditioning of Aplysia. J Neurosci 9:42364245 .

Hawkins RD, Castellucci VF, Kandel ER (1981a) Interneurons in- volved in mediation and modulation of gill-withdrawal reflex in Aplysia. I. Identification and characterization. J Neurophysiol 45:304 314.

Hawkins RD, Castellucci VF, Kandel ER (1981b) Interneurons involved in mediation and modulation of the gill-withdrawal reflex in Aplysia. II. Identified neurons produce heterosynaptic facilitation contributing to behavioral sensitization. J Neurophysiol 45:315-326.

Jacklet JW, Rine JJ (1977) Facilitation of neuromuscular junctions: contribution to habituation and dishabituation of the Aplysia gillwithdrawal reflex. Proc Natl Acad Sci USA 74:1267-1271.

Kupfermann I, Carew TJ, Kandel ER (1974) Local, reflex, and central commands controlling gill and siphon movements in Aplysia. J Neurophysiol 37:996-1019.

Lloyd PE, Mahon AC, Kupfermann I, Cohen JL, Scheller RH, Weiss KR (1985) Biochemical and immunocytological localization of molluscan small cardioactive peptides in the nervous system of Aplysia californica. J Neurosci 5:1851-1861.

Montarolo PG, Goelet P, Castellucci VF, Morgan J, Kandel ER (1986) A critical time-window for macromolecular synthesis in long-term heterosynaptic facilitation in Aplysia. Science 234:1249-1254.

Pinsker H, Kupfermann I, Castellucci VF, Kandel ER (1970) Habituation and dishabituation of the gill-withdrawal reflex in Aplysia. Science 167:1740-1742.

Rosen SC, Susswein AJ, Cropper EC, Weiss KR, Kupfermann I (1989) Selective modulation of spike duration by serotonin and the neuropeptides $\mathrm{SCP}_{\mathrm{B}}$, buccalin and myomodulin in different classes of mechanoafferent neurons in the cerebral ganglion of Aplysia. J Neurosci 9:390-402.

Schacher S, Montarolo P, Kandel ER (1990) Selective short- and longterm effects of serotonin, small cardioactive peptide, and tetanic stimulation on sensorimotor synapses of Aplysia in culture. J Neurosci 10:3285-3294.

Simmons LK, Koester J (1986) Serotonin enhances the excitatory acetylcholine response in the RB cell cluster of Aplysia californica. $\mathbf{J}$ Neurosci 6:774-781.

Tauc L, Gerschenfeld HM (1962) A cholinergic mechanism of inhibitory synaptic transmission in a molluscan nervous system. J Neurophysiol 25:236-262.

Walters ET, Byrne JH (1984) Post-tetanic potentiation in Aplysia sensory neurons. Brain Res 293:377-380.

Walters ET, Byrne JH (1985) Long-term enhancement produced by activity-dependent modulation of Aplysia sensory neurons. J Neurosci 5:662-672.

White JA, Cleary LJ, Ziv I, Byrne JH (1991) A network model of the tail-withdrawal circuit in Aplysia. Soc Neurosci Abstr 17:1590.

Wright WG, Marcus EA, Carew TJ (1991) A cellular analysis of inhibition in the siphon withdrawal reflex of Aplysia. J Neurosci 11: 2498-2509. 